\title{
Erratum to: Strategies to obtain pattern fidelity in nanowire growth from large-area surfaces patterned using nanoimprint lithography
}

Gaute Otnes, Magnus Heurlin, Mariusz Graczyk, Jesper Wallentin ${ }^{\dagger}$, Daniel Jacobsson ${ }^{\ddagger}$, Alexander Berg, Ivan Maximov, and Magnus T. Borgström ( $\square)$

Solid State Physics, Lund University, Box 118, S-221 00 Lund, Sweden

${ }^{\dagger}$ Present address: Division of Synchrotron Radiation Research, Lund University, Box 118, S-221 00 Lund, Sweden

F Present address: nCHREM/Centre for Analysis and Synthesis, Lund University, Box 124, S-221 00 Lund, Sweden

(C) Tsinghua University Press and Springer-Verlag Berlin Heidelberg 2016

\section{Erratum to}

Nano Research 2016, 9(10): 2852-2861

DOI 10.1007/s12274-016-1165-z

The unit of $y$ axis in Fig. 2 in the original version of this article was unfortunately wrongly written on page 2856, instead of $\mathrm{m}^{-2}$.

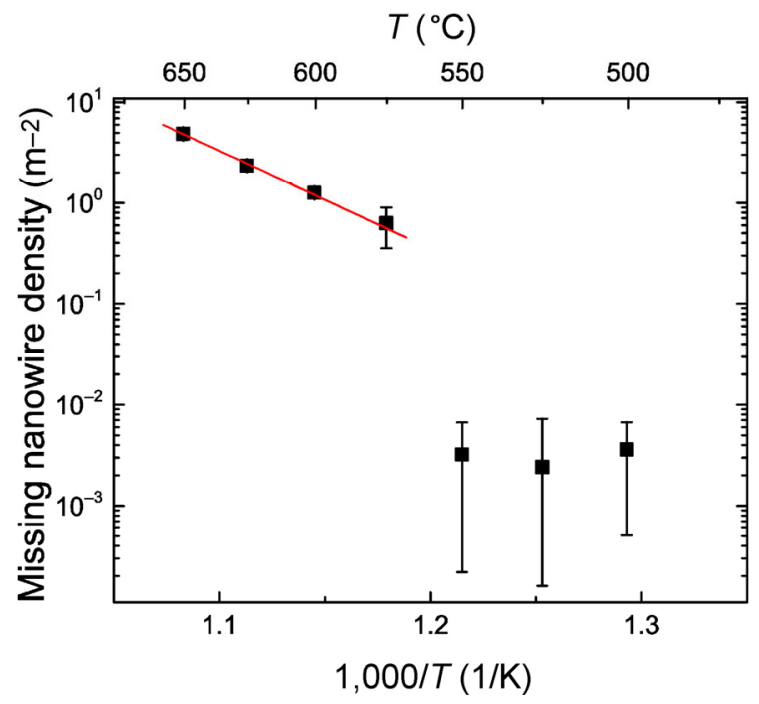

The online version of the original article can be found at http://dx.doi.org/10.1007/s12274-016-1165-z
It should read $\mu \mathrm{m}^{-2}$.

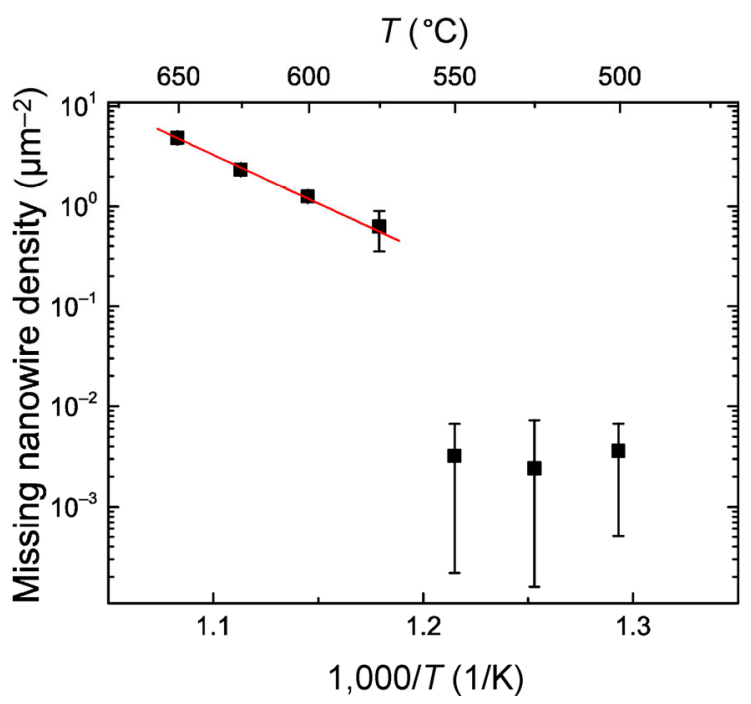

Address correspondence to magnus.borgstrom@ftf.lth.se

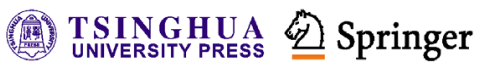

